\section{(T) oxe}

\section{AN EARLY HELICOPTER.}

\section{To the Editor of the SoIDVTIIC AmerICAV:}

I send you a brief account of the experiments in flying machines made about fifty years ago by my
father, the late George $W$. Dow of Brooklyn, N. Y. He always had great faith in aerial navigation, and frequently asserted that when an engine should be con-
structed light enough and with sufficient power, it would be accomplished. His experiments were recently recalled to me, when I discovered among his
papers a wood-engraving block which was used by papers a wood-engraving block which was used by
your valuable paper about fifty years ago in publishyour valuable paper about fifty years ago in publishpropellers that working vertically raised the car, tion, would carry it forward or steer as desired. I go one of my humming tops ir. $t$ wo; and my subsequent
delight. when, after fastening blades or wings at an angle on the surface and using the spinning handle inversely, he caused it to soar gracefully into the air.
Following this experiment he made a smali model Following this experiment he made a smali model
with four propellers on vertical shafts in the corners, with four propellers on vertical shafts in the corners,
and which easily flew about the room by means of clockwork. machinery. It was shortly after your pubtop appeared from France, and I remember his quescation or if, as not infrequently happens in the world's inventions, some Frenchman had been working at the same time on similar lines. At the present day en-
gines light enough and strong enough having been made, my father's prophecy seems about being ful-
filled; and it is not improbable that the lifting and filled; and it is not improbable that the lifting and
steering will be accomplished in the manner which he
conceived, perhaps in conjunction with some kind of conceived, perhaps in conjunction with some kind of successful prominence.
Wakefield, N. H.

Aвbot Low Dow.

\section{SLIPPING OF WHEELS ON CORVES.}

To the Editor of the Scientific American:

I am a constant reader of your paper, and consider it one of the best publications in America, but have in your description of the Alaska-Yukon Exposition is the highest mountain in the United States. California can lay claim to that distinction in Mount is the highest outside of Alaska. I live in the shadow of this mountain, and like all other residents

Another is the often-asked question about the train going around the curve, and the outside wheel being Your answer has been that the inside wheel would have to slip. I beg to differ with you, for the following reason: When the train is going around the curve, wheels to hug the rails close to the flanges of one inside curve is natiurally a way from the flange of the from it conent wheel on the outside rail while going around the curve is greater I think you will have no trouble in seeing the point.
Visalia, Cal.

[When a train is rounding a curve, the resultant of gravity and centrifugal force inclines toward the outer rail. This produces an increased frictional resistance
between the outer wheels and the euter rálil, both on between the outer wheels and the outer rálil, both on
the tread and the flange. As the resistance to slipthe tread and the flange As the resistance to slip-
ping is, other things being equal, proportional to the pressure, the inner wheels will be the first to slip. that the outer wheel can travel a longer distance than that the outer wheel can travel a longer distance than
the inner without the latter slipping, because the outer the inner without the latter slipping, because the outer
wheel rolls on a larger circumference of the coned sursufficient to make the difference, and has in recent years been reduced.-ED.]

\section{SOME MORE LUNAR SOPERBTITIONS.}

To the Editor of the Scientific AMERICAN:

Reading your article, "Lunar Superstition and Potatoes," calls to mind many other equally as superstiin the moon, kill hogs in the moon, deaden timber, build a fence, and do almost everything by the moon. As a basis many refer to the Scripture, Genesis, first
chapter, fourteenth and sixteenth verses. But few people realize that the moon is as large when it is on the same amount all the time; and it is owing to position that makes the different phases of the moon. position semi-scientific men claim that if corn is planted in the dark of the moon, when it comes up the nights are light and cause it to grow faster. Many regard the moon as a weather indicator. If it is on its back it is on its point, the water has all spilled out and it will be a dry moon. Being north or south of an eastern or western line indicates cold or warm weather, not realizing that it has its regular path, and is ap-
proximately in the same position at the same time of McKenzie, Tenn.

W. R. CaAwford

\section{SIGNALING TO TARS WITH MIRRORS.}

To the Editor of the Screntific A MERICAN:
In the Scientific AMERICAN of May 15th, in an article on "Signaling to Mars," are these statements "A correspondent of the New Yorrs Sun, who states
that he is a practical heliograph man, calls attention to a fact which seems to have been overlooked. The heliograph man points out that a pocket mirror two inches square will do as much work as a mirror is to reflect a single image of the sun. He states that it is possible to flash from 6 to 48 miles with a shaving glass."

I have been thinking on the subject, and would like to submit the following. If there is any
with the reasoning, please correct me.

Any plane mirror will reflect all of the sun's rays
hat fall upon it. Every boy has thrown sunlight the wall or ceiling by a piece of glass. The spot of reflector, whether that be an irregular piece of glass, a shaving glass, or the family "looking glass." Those single image of the sun, and that image will be large or smaller, according to the distance of the mirro The the eye.

The diameter of the sun is about 32 min., circu lar. measure, so 32 min. will be the "angle of vision"
subtended by the sun. A little figuring will show that the arc of $32 \mathrm{~min}$. is 0.0093 of the radius of a circle. If we consider the eye as the center of a cirTherefore a mirror held at a distance from the eye will not take in a full image of the sun unfless it hàs an angùlar diameter of 32 min. or an abso

At $a$ distance of one yard, this diameter will be 0.33 inch; that is, the image of the sun, reflected in a mir-
ror one yard away, will be about one-third of an inch ror one yard away, will be about one-third of an inch to 11.16 inches in diameter, and a mirror placed one mile distant would need to be 49.1 feet to reflect a full image of the sun. Every additional mile of distance the mirror. To reflect millions of miles would requir a very large mirror to give a full image of the sun;
" 2 -inch" or à " 10 -foot" mirror certainly would not. This can be verified by observing the reflection of the to the window, he will see a small, round image of to the window, he will see a small, round image of
the sun; as he recedes from the window this image will increase in size, and at a distance of 50 or 75 rod the entire window will be lighted up with a single image of the sun. Often, while standing at the Penn-
sylvania Ferry in Jersey City, I have observed the im.
age of the setting sun reflected from the high office age of the setting sun reflected from the high office
buildings of New York, one mile distant, and that imag extended over several windows. The shaving glass, or heliograph reflector, 4 inches in diameter, if more than 40 feet from the observer, will not reflect an entire
image of the sun. While it may "flash a signal from 6 small portion of the full image of the sun.

smom this we see that the amount of light reflected from a distant mirror is directly proportional to the
surface of the reflector, and in signaling to Mars, large mirrors will be more powerful than small ones. success, these are beyond the range of mathematics. Elizabeth, N. J.

\section{The Current sipplement.}

A new departure in locomotive construction is de scribed in the opening article of the current SuppLEIIENT, No. 1743. The locomotive in question is fired with liquid fuel, and can be reversed without the use of any intermediate gearing, both the power and speed being controlled by altering the steam charge in the cylinder, without resorting to the expedient of different ratios of transmission. George $P$. Floyd, an oldtime railway conductor, describes most interestingl the life of early conductors, men who were usually recruited from the ranks of stagecoach drivers. A Japanese engineer, Wadagaki, has made the suggestion of using the exhaust steam from the main en gines in a turbine which should drive a turbo-com pressori, taking the steani from the boilers and delivering it to the main engines in a compressed an superheated condition. $A \cdot$ critical comment on this scheme is published. The successful management of equipment with depends upon the efficiency of th repair of the equipment is a vital consideration. $\mathrm{Mr}$. W. R. Beattie tells how the equipment can be kept in good order. James Arthur writes on ancient chariot wheels, and shows that the wheel can be traced back 3,500 years. Herbert Chatley's splendid paper on aero problems is concluded. Prof. F. Henrieh reviews recent work in radio-activity. The pearl-button industry writes on magnetic ore separation and the electrica operation of mining machinery. The usual engineering notes, trade notes, and science notes will be found in their accustomed places.

The gasoline tank should be filled through a hose connection from the pump, or if, as in the largest garages, it is impracticable to run the cars to the pump; a portable tank on wheels, of a capacity of about fifty gallons, fitted with a pump to which is attached a hose, should be used. The portable wheel tank is run to the pump and filled, and can then be moved from car to car. Either of these methods of filling tanks reduces the fire risk to a minimum, as the gasoline is not exposed to the air, and cannot vaporize. These methods do away with the excuse for open pails and buckets partially filled with gasoline, and constantly giving off explosive vapor. The workmen should not be allowed to use gasoline for washing their hands or cleaning the cars. In either case the gasoline is pumped or poured on the floor and allowed to evaporate. To prevent this, the pump should be equipped with a lock, and the key kept by the foreman, or man in charge, so as to prevent the pumping of gasoline on the hands.
THE YANOFACTORE OF FRENCH POSTAGE STAMPS.

All of the postage stamps, postal cards, letter cards, money orders, and pneumatic cards and envelopes which are used in France and the French colonies are made in the national factory in the Boulevard Brune, Paris, by 320 employees, men and women, who are appointed. by the Secretary of Posts and Telegraphs. With the aid of the improved machines which are shown at work in the accompanying photographs, this small force of selected workers turns out the immense quantity of matter detailed below. The figures are for the year 1907.

Postage stamps (of which 1,500 millions are of the denomination of 10 centimes,

equiva.lent to 2 cents) $\ldots \ldots \ldots \ldots \ldots \ldots, 2,700,000,000$

Postal cards ........................ 20,000,000

Letter cards ....................... 45,000,000

Pineumatic cards . .................. 4,000,000

Pneumatic envelopes ............... 400,000

Domestic money orders bound in books

of 50 or $200 \ldots \ldots \ldots \ldots \ldots \ldots \ldots \ldots \ldots, 45,000,000$

International money orders........... $2,000,000$

Colonial stamps .................. $50,000,000$

In making postage stamps, the first step is to order from a celebrated artist the design of the engraving. The design is drawn on a large scale, and reduced by photography to the exact dimensions of the stamps. The reduced image is given to a skillful engraver, who engraves it upon wood or steel. When this engraving has been approved by the artist, it constithes the original plate. From this plate, which does not bear any mark of value, an impression is taken n wax, if the plate is wood, or in lead if the plate is steel, and from this impression electrotypes are made. The electrotypes, having been carefully retouched, go back to the engraver, who inserts the figures of value. Thus is obtained a series of plates corresponding to the different denominations of stamps. From each of these plates impressions in lead are taken. These are grouped in fifties, and thus electrotyped. In order to strengthen the thin sheet of copper, which forms the "shell," or electrotype, its edges are turned up. and a backing of melted type metal is poured upon it. The plate thus obtained, after being further retouched by the engravers, is ready for printing.

One of our photographs shows ärtists examining shells with a lens, and erasing small defects with the burin.

The printing is done by the usual methods but, naturally, with very great care. Each sheet of stamps contains 300 or 600 stamps, and the operator must assure himself that every portion of the six or twelve engraving plates shall be subjected to exactly the proper degree of pressure. In this way it sometimes happens that several days elapse between the arrival of forms at the press and the actual impression.

The presses are of two different types, platen and cylinder. The former work less rapidly than the cylinder presses, and are used particularly for printing stamps in several colors. In order to facilitate the control of the operation, the edge of every sheet has impressed upon it the date, the number of the press, and the letter designating the pressman. We ghall not go into details concerning the presses, most of which resemble those found in other modern pressrooms, but we shall describe more particularly the new rotary press designed by the Marinoni firm, for the purpose of printing money orders and postal notes, and purchased by the government at the commencement of 1908

Previously, French money orders and postal notes had been printed on flat presses of various types, not printing more than 1,000 per hour, and afety background, the main design, the numbers in color, the serial numbers in blaek, and the black in black). The new Marinoni press performs all these operations at once, and delivers sheets of ten money orders, completely printed and numbered, at the rate of 6,000 or 8,000 sheets per hour. The operation of the machine is shown in one of the photographs. A continuous band of paper, running from a reel, re ceives a first impression from a cylinder which carries the plates of the safety background, and a second impression on the face from another cylinder carrying the engravings of the main design. Simultaneously a series of printing drums carry numbers of three figures, which change at each turn of the press cylinder and are printed in color on the paper. On another series of drums are the numbers of six figures, which change for each fifty or one hundred heets. A special mechanism allows this numberin to be done without any shock, despite the great speed of rotation. The serial numbers in black are im pressed as the band unrolls, and at the same time the back receives its impression from two other cylin ders. The printed blank is then cut into sheets, each containing ten postal orders, which are automatically arranged in piles of five and placed on a table which moves once for each one hundred sheets, so that the 
money orders which are to form a book are properly arranged and numbered and need only be cut from the pile of printed sheets. In order to arrange conveniently all these sheets by the old system, it is necessary to have an assembling table, behind which stand men who take a sheet from each pile as it passes before them. When the revolution is accomplished. the book of money orders is complete. It is then taken to the binding machines, which fasten it with three wires and put on the cover.

To return to postage stamps: The printing finished, they are counted and go to the gumming machine, where an operator places the sheets on a cylinder which presses them against the gum roller. After this the sheets are seized by claws and carried by a long chain into the drying apparatus, which is formed of a series of vertical shafts of metal containing gas burners for the purpose of heating the air, which is lept in motion by fans In these machines the sheets travel 350 to 400 feet in about ten minutes and are then dry. The two boys who receive them from the gumming machine have only to pile them regularly on the table. The gummed sheets, after being again counted, go to the perforating room, where they are perforated very rapidly by a machine. The sheets are cut in two or four pieces according to size, and instantly punches out thousands of minute disks. The 600 stamps are perforated in less time than it takes to describe the operation. The stamps then leave the factory for the storehouse of the responsible agent, where they are again counted.

In addition to postage stamps and money orders the government factory makes pneumatic envelopes, pneumatic cards or "petits bleus," stamped newspaper wrappers, letter cards, and postal cards. The envelopes and "petits bleus" are cut out by hundreds from the printed sheets. Then a girl inserts the pieces separately in an apparatus which folds and fastens them. The flap is then gummed by another machine. A workman lays the envelopes on long strips of canvas which, moving continuously, carries them to the gum roller and then to other endless bands arranged horizontally over a distance of 130 feet. At the end of this journey the envelopes, now dry, fall upon other
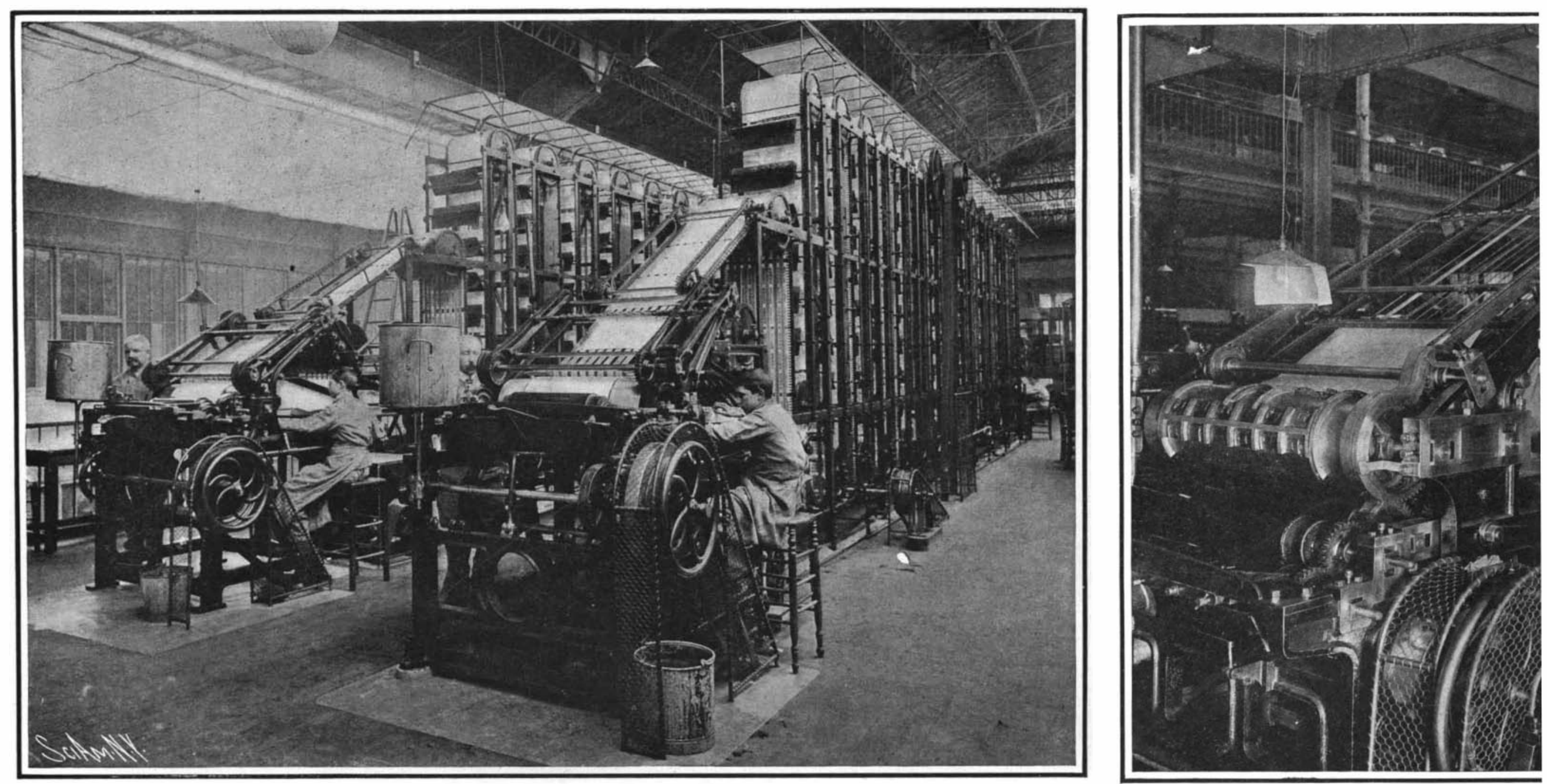

Fig. 1.-Gumming sheets of postage stamps by machine.

Fig. 7.-Machine for gnmming a
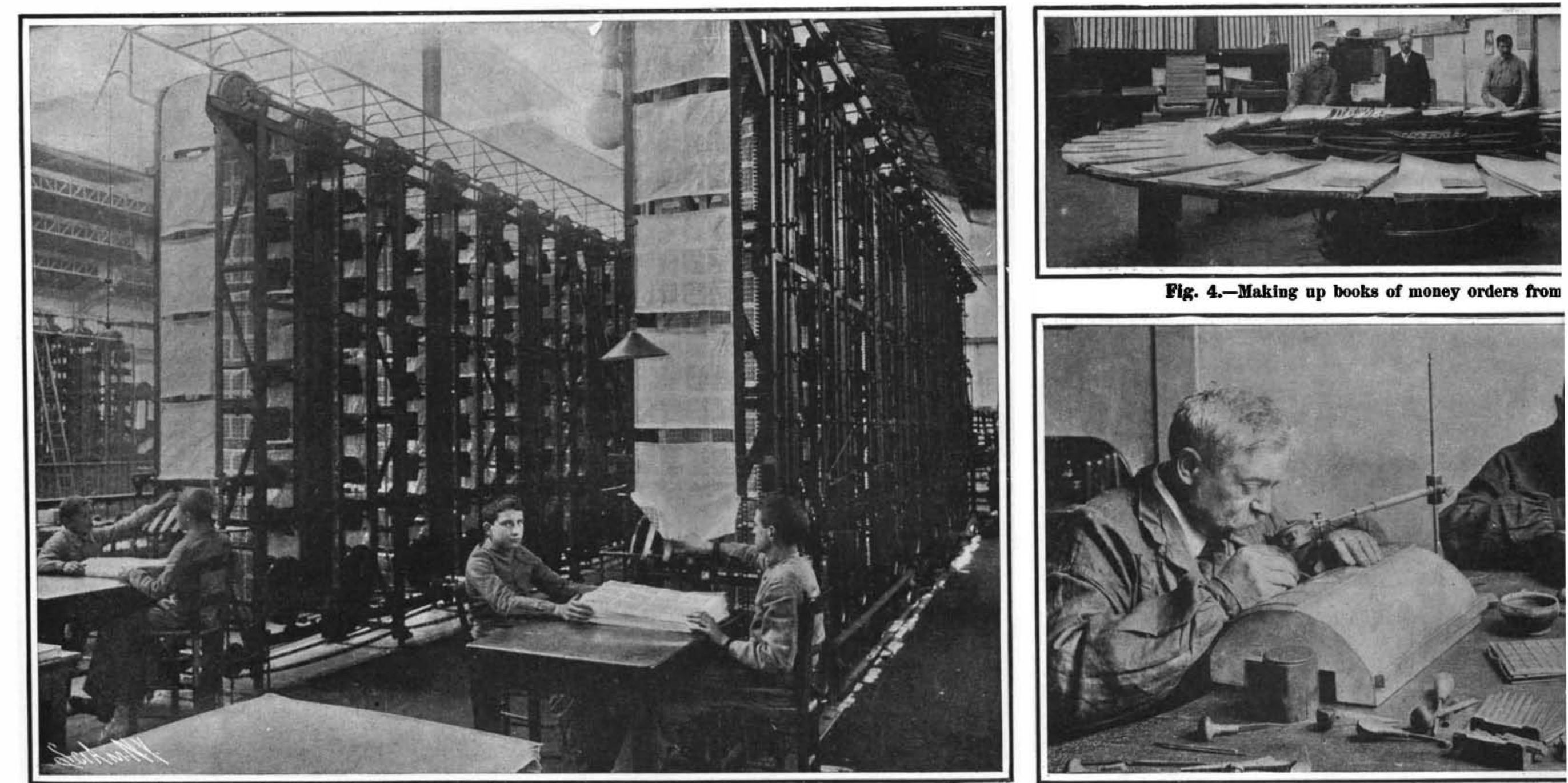

Fig. 4.-Making up books of money orders from

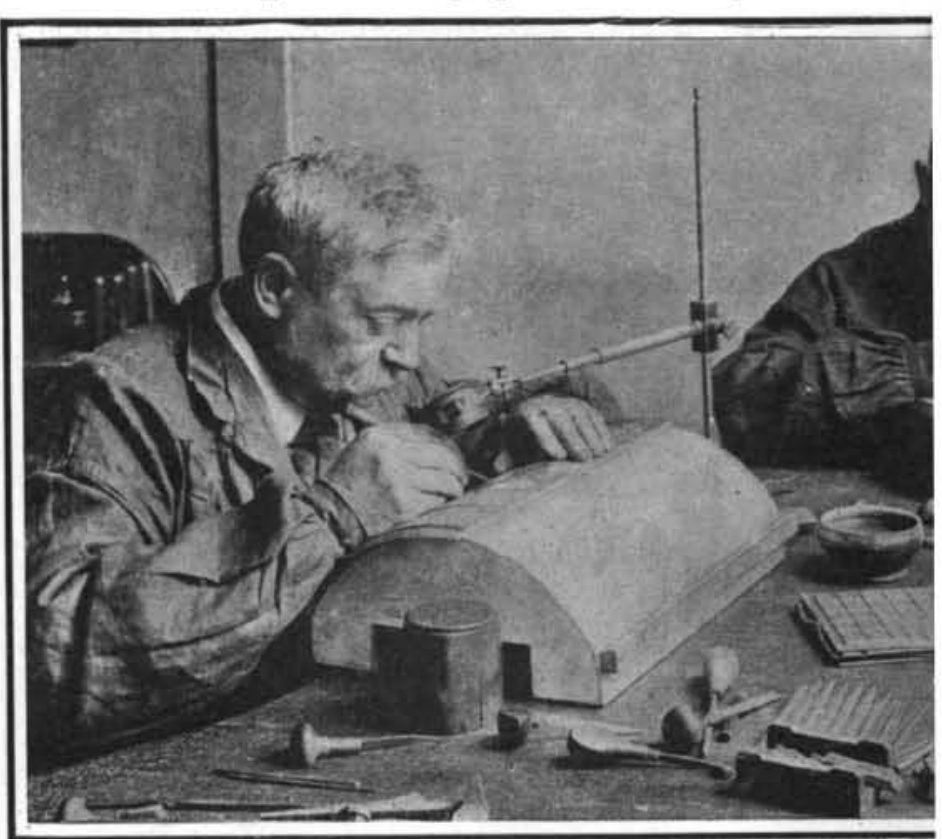

Fig. 8- The drying apparatne.

Fig. 5.-Engraving the plates from which postag

THE MANUFACTURE OF FREI 


\section{herican}

ands of canvas moving within reach of a man who lles the envelopes on a table. The stamped wraplers are made more easily. After printing they are ummed with a brush operated by hand, and placed a racks to dry. The letter card department requires complicated apparatus and long operations. The ards must be printed, cut, folded, gummed and perorated. The perforation is for the purpose of faciliating the opening of the cards after they have been ealed. The folding is done with a small machine perated by a boy, who lays each card on a plate, over slit, into which the card is forced by the descent of dull knife moved by a treadle. In this way one boy an fold from 4,000 to 10,000 letter sheets in eight hours. The gumming is done in the same way as in the case of the envelopes. The operator in charge of the perforater has nothing to do but to present the folded card to the teeth of the machine.

Postal cards are printed on fiat presses from copper plates and are then cut out with a wheel, counted, and packed.

It should be observed that with a selected but very small force of workers, whose daily wages are about 40 cents for boys, 65 cents to $\$ 1.05$ for women, and $\$ 2$ at most for men, the government manufactures postage stamps at the extremely low cost of about 20 centimes or 4 cents per thousand; thus the 10-centime stamp sells for 500 times its actual value. These are advantages that are scarcely found to-day in the most

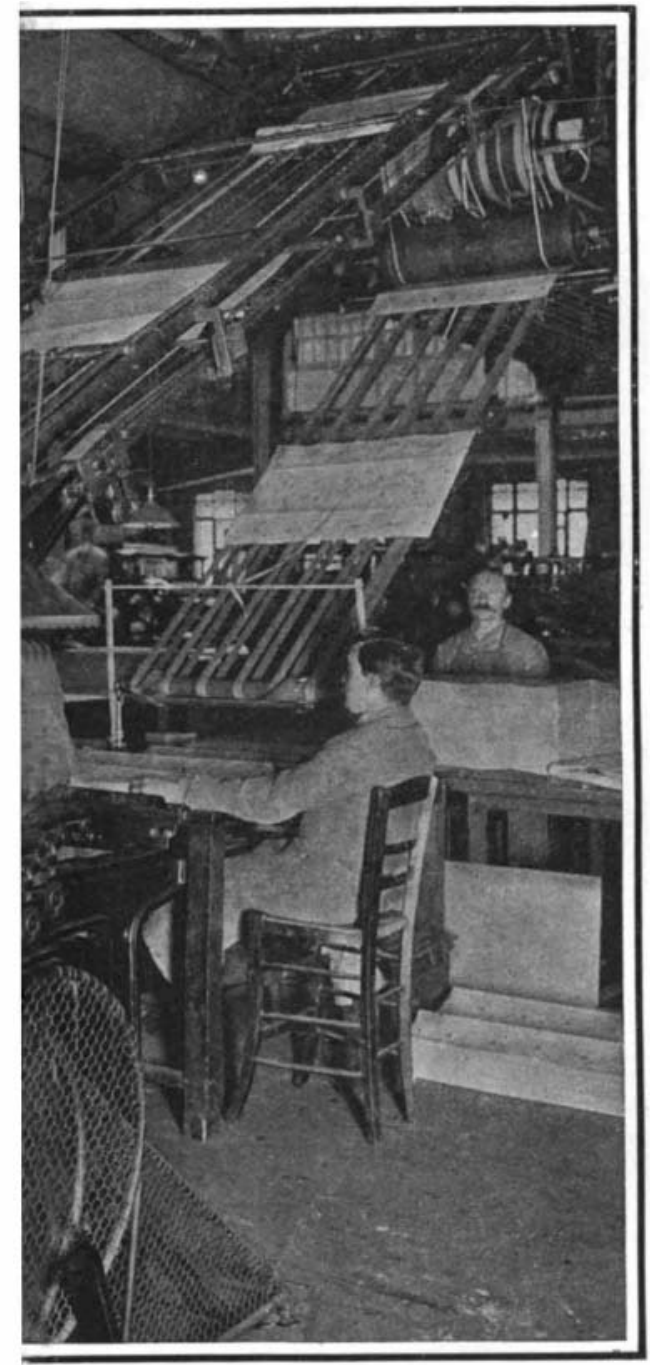

nd drying letter cards.

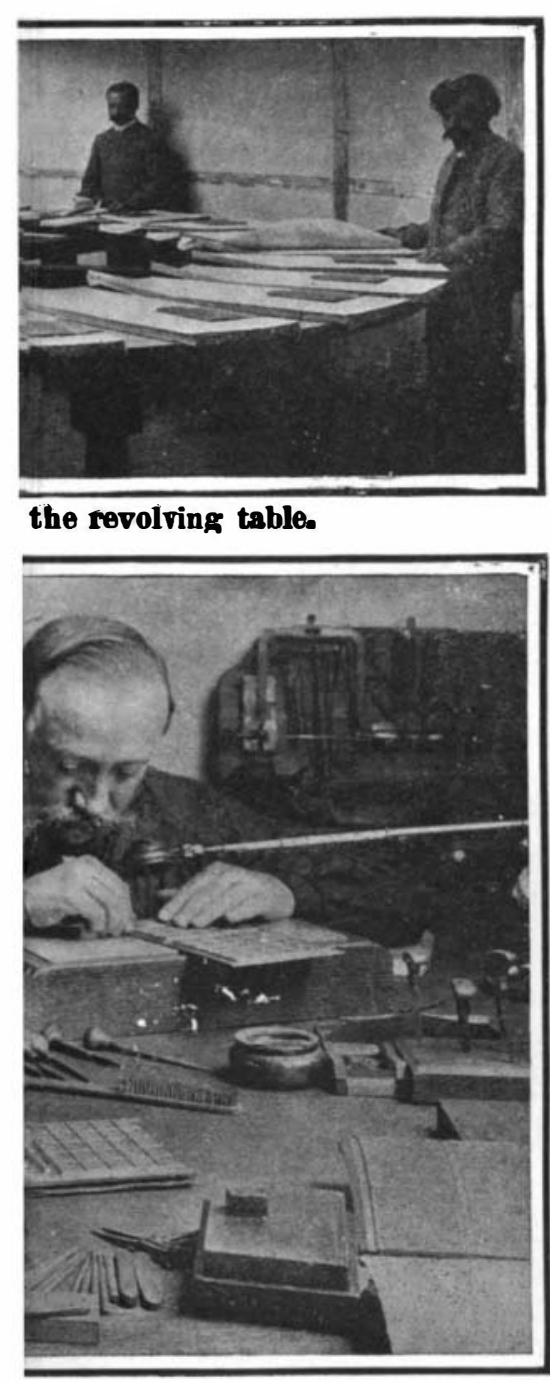

re stamps are printed.

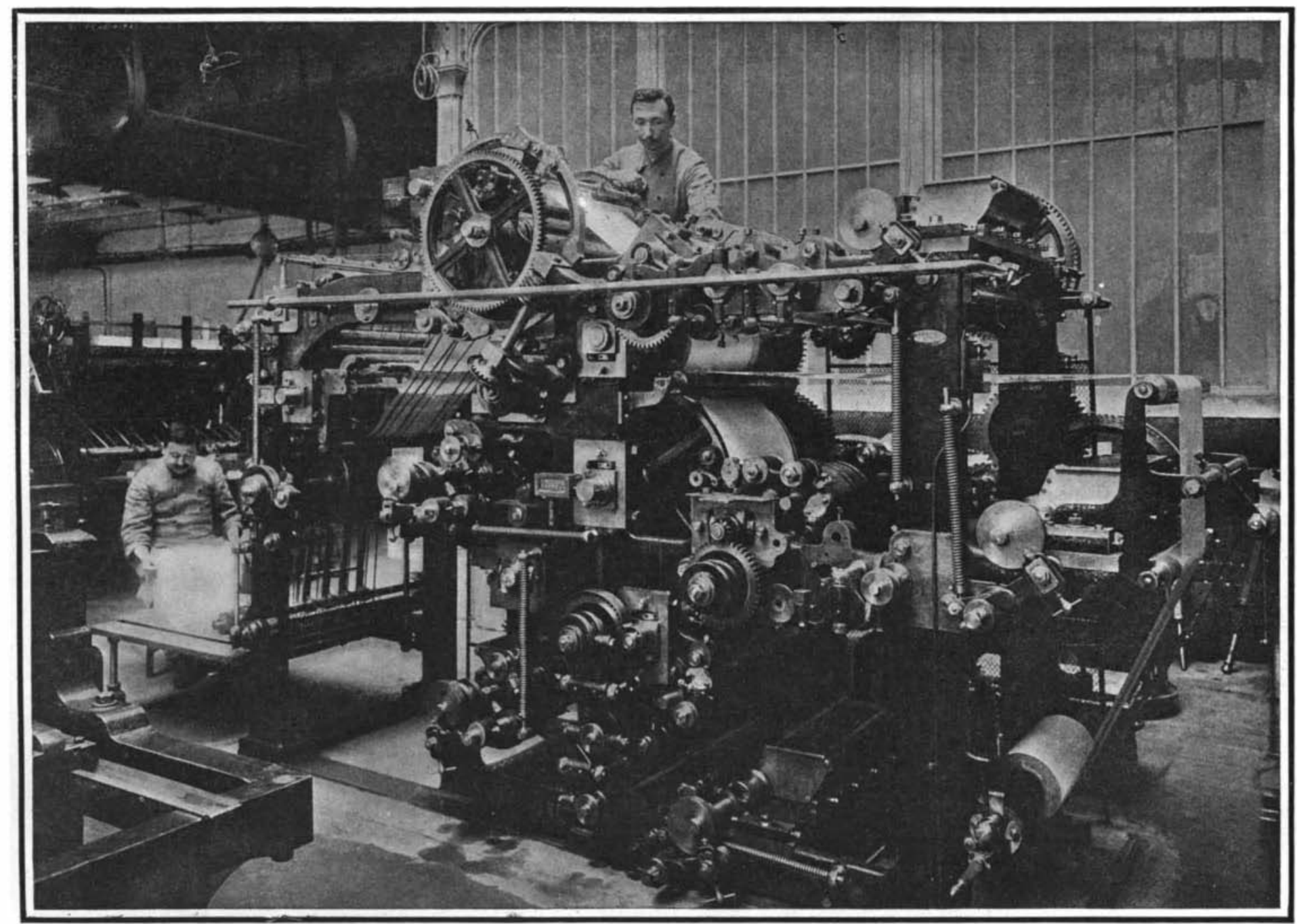

Fig. 8.-Printing money orders on the Marinoni cylinder prese

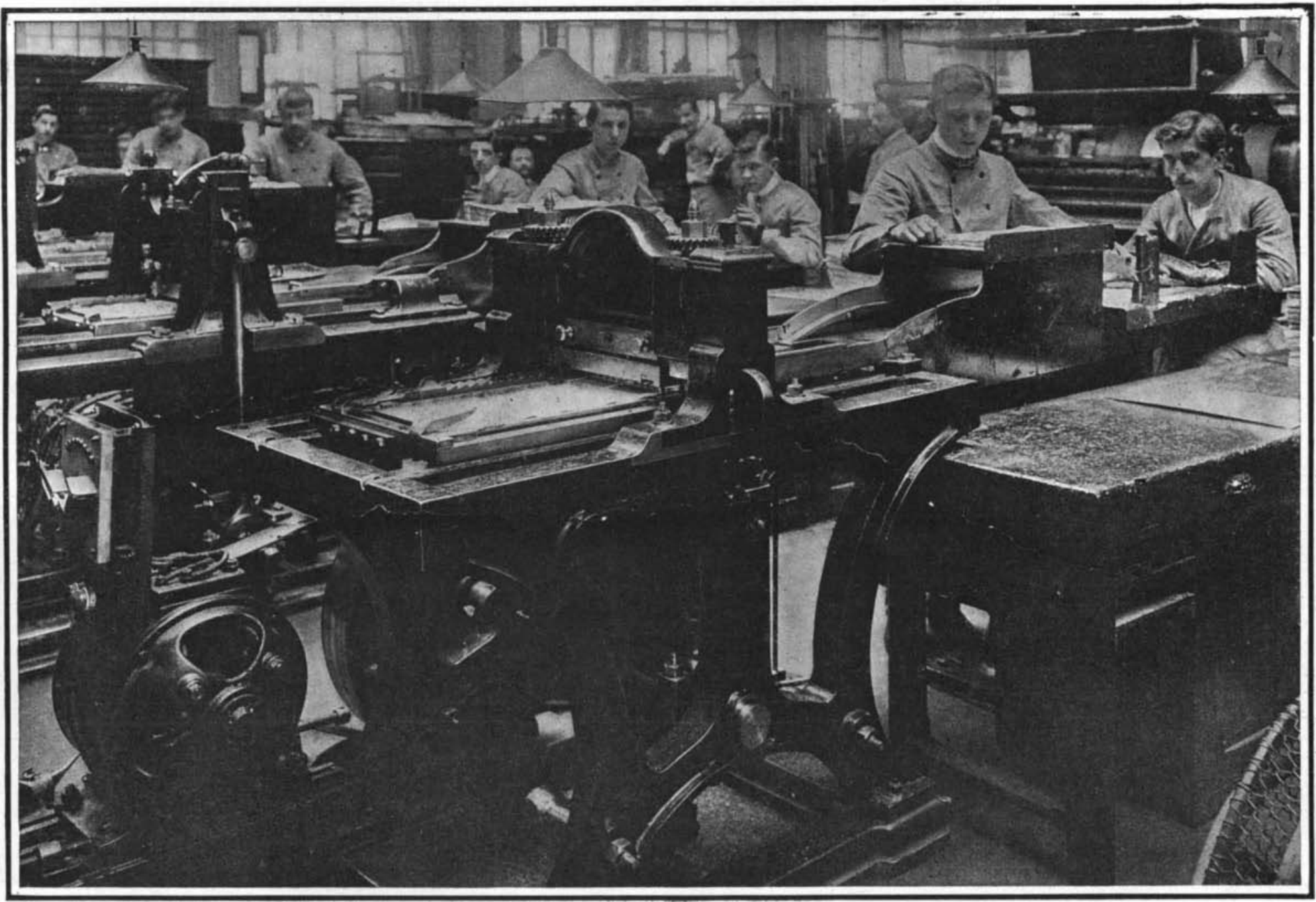

Fig. 6.-The perforating machines. 